\title{
Un lugar en Europa y en el Mundo. Portugal y la geopolítica internacional durante la regencia de Pedro de Braganza (1668-1683)
}

\author{
DaVid MaRTín Marcos* \\ UNED
}

\begin{abstract}
Making a place for itself in Europe and in the world: Portugal and the international geopolitical scenario during Peter of Braganza's regency (1668-1683)
\end{abstract}

\begin{abstract}
RESUMEN ABSTRACT
A menudo el Portugal «post-restaurado» ha sido visto como un escenario donde los poderes del continente entablaron una lucha por ganarse un aliado. Esa idea se ha visto alimentada por la imagen del regente don Pedro, supuestamente inestable e incapaz de optar por un posicionamiento franco en el continente. Este artículo trata de demostrar que detrás de la apariencia de un príncipe débil que ofrecieron muchos de sus coetáneos, se escondió una estrategia para asegurar la propia pervivencia de Portugal. Como se verá, en esa circunstancia tuvo mucho que ver las peculiaridades de su regencia, muy diferente de los modelos clásicos en que el poder de sus titulares suele tener de antemano una fecha límite. Defendemos, pues, que el hecho de estar llamado a ocupar el trono regio a la muerte

de su hermano, favoreció un poder, débil inicialmente, que se afianzó con el paso del tiempo.

«Post-Restoration» Portugal has been traditionally considered a scenario where European powers entered a race to find an ally. This idea has been fed by the image of Regent Peter, supposedly instable and unable to take a clear stand in Europe. This article aims to show that, behind the appearance of a weak prince given by many of his contemporaries, there was a strategy to ensure Portuguese's survival.

As will be discussed later, this circumstance was strongly related to the peculiarities of Peter of Braganza's Regency - too distant from classical models, in which holders are characterized by having a cut-off date-. In this case, the fact that

Peter was the first in the line to the throne encouraged him over time to mitigate his weaknesses.
\end{abstract}

* Investigador del programa «Juan de la Cierva» (JCl-2010-06893), integrado en los proyectos de investigación: Repensando la identidad: la Monarquía de España entre 1665 y 1746 (HAR2011-27562/ HIST) y Conservación de la Monarquía y equilibrio europeo entre los siglos XVII y XVIII (HAR2012 37560 C02-01). 


\section{PALABRAS CLAVE: KEY WORDS:}

Portugal, Pedro de Braganza (Pedro II), Regencias, Política internacional, Siglo XVII.
Portugal, Peter of Braganza (Peter II), Regencies, International Politics, Seventeenth Century.

\section{ENTRE LA GUERRA Y LA PAZ}

Desde que en 1415 las tropas de Juan I de Avis conquistaron la ciudad de Ceuta, el reino de Portugal se erigió en un ente político particular. De discreto peso en el continente europeo pero con un imperio que adquiriría dimensiones descomunales en América, África y Asia, el gobierno de Lisboa forjó un binomio célebre con los océanos como vínculo vertebrador, que le acompañó durante siglos marcando su propia configuración y que, de la lejana Goa a las costas de Brasil, de las tierras de Olivenza a la isla de Madeira, halló en el periodo de los Austrias un momento que un tipo de discurso nacionalista quiso considerar ajeno y crítico. Origen de supuestos males que perduraron en la memoria, en la actualidad el tópico sobre el pretendido hiato que tuvo lugar en la historia portuguesa durante los reinados de los Felipes ha quedado superado gracias en parte a los trabajos de la propia historiografía lusa1. Partiendo de un doble proceso de agregación territorial y concentración del poder en el centro y no del debate sobre los conceptos de centralización y descentralización ${ }^{2}$, aquí se sostiene, no obstante, que el carácter dual de lo portugués estuvo en riesgo. No obstante, para ello, no se achaca estrictamente tal circunstancia a una sumisión de los territorios ultramarinos a la Monarquía sino más bien a una supeditación de Lisboa a los designios de Madrid en los asuntos relativos al Viejo Mundo. De hecho, a pesar de las intromisiones de la Corona en las «conquistas» durante la época hispana ${ }^{3}$, condicionada la parte continental del todo y perceptible el surgimiento de un fuerte sentimiento localista ${ }^{4}$, cabe relacionar la quiebra de la concepción bipartita a la inclusión de Portugal en una estructura mediadora con Europa como era el entramado de los dominios habsbúrgicos.

Fue la integración la que hizo que los canales de la comunicación oficial para los negocios del otro lado de los Pirineos, frente a las alternancias de los itinerarios terrestre - generalmente vía Madrid - y marítimo - a través de Londres, La Rochelle o Hamburgo - que habían caracterizado al Portugal alto-moderno, quedasen adscritos casi exclusivamente al control español y, por ende, al camino ibérico. Sin representaciones diplomáticas de primer nivel, Lisboa agudizó su dependencia y de algún modo su aislamiento, y quizás por ello aumentaron en sus

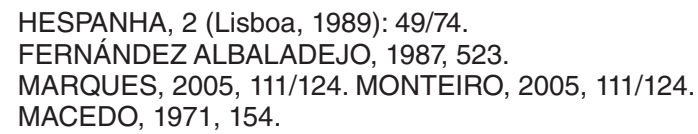


calles voces críticas que reclamaron hacer de la ciudad del Tajo la verdadera capital de la Monarquía hispánica ${ }^{5}$. Por eso, cuando en diciembre de 1640, se desató la rebelión contra los Habsburgo y el duque de Braganza fue aclamado como Juan IV de Portugal, a la guerra con los españoles en la península lbérica y a la reconquista de las plazas del noreste brasileño, en manos de los holandeses desde la década anterior, les acompañó también la pragmática y menos heroica reconstrucción de una red diplomática capaz de obtener el reconocimiento total de la nueva dinastía ${ }^{6}$, aderezada por una leve reapertura cultural hacia lo que el historiador Luis Reis Togal dio en llamar la «Europa transpirenaica»?.

Sellado el proceso con la aceptación por parte de la corte de Madrid del nuevo statu quo en el tratado de Lisboa de 1668, se abrió entonces ante el gobierno bragancista una nueva época que en apariencia debía retrotraerle al periodo anterior a 1580, año en que, ya fuera por pactismo o por la amenaza de la violencia tras la muerte de D. Sebastián en Alcazarquivir (1578), la extinción de la dinastía de Avis había desembocado en la integración de Portugal en la Monarquía hispánica ${ }^{8}$. Una etapa, ahora, en la que la guerra en la Península y sus inherentes condicionantes quedaban atrás.

En ocasiones se ha señalado que los Braganza, por una inequívoca vocación atlántica del reino, procuraron a partir de ese momento el amparo de Londres. Lisboa ya lo había hecho en tiempos pasados jalonados por hitos tan significativos como la victoria de Aljubarrota o los acuerdos de Windsor a finales del siglo XIV, y la historiografía, azuzada por el tratado de Methuen de 1703, en un ejercicio de teleología desmesurado ha querido ver en el último tercio del Seiscientos demasiados indicios de anglofilia en la corte $^{9}$. De alguna manera como si la política exterior de la regencia y buena parte del reinado de D. Pedro II de Braganza tuviese que ser explicada en base a algo que aún estaba por suceder. Aunque lo cierto es que si por algo se caracterizaron esos años fue por la equidistancia que demostró Lisboa para con los grandes poderes del continente por más que hubiese sido en última instancia Londres quien hubiese ejercido de mediadora y garante en la reciente paz hispanolusa. Al fin y al cabo, y teniendo en cuenta que para los portugueses la «amenaza española» nunca se desvaneció, Francia se erigía en un contrafuerte mayor que Inglaterra frente a las supuestas pretensiones de los Austrias haciendo ver a Madrid que siempre cabía recurrir a París en caso de agresión mediante una alianza que, pese a todo, en un meticuloso ejercicio de equilibrio, jamás llegaría a concretarse.

5 BOUZA, 13 (Lisboa, 1994): 71/93.

6 CARDIM, 19-20 (Lisboa, 1998): 101/128. LEAL DE FARIA, 2005.

7 TORGAL, 1981, 113/114. MIRANDA, 123-124 (São Paulo, 1990/1991): 35/70.

8 BOUZA, 1987, 207/478. VALLADARES, 2008. RUIZ IBÁÑEZ y SABATINI, 81 (Chicago, 2009): $501 / 536$.

9 COSTA, 2003, 39/49. 
Si el último siglo había estado marcado por las tensiones entre las dos grandes Casas reinantes del continente, los Habsburgo y los Borbones, y el creciente dominio naval de Inglaterra y las Provincias Unidas, a Portugal le resultaba difícil posicionarse por cuanto sus propios intereses encontraban rivalidades particulares ya fuera en ultramar o en Europa y, sobre todo, poco útil en términos políticos y económicos tras la debacle que había supuesto para su hacienda la larga guerra con España. Por lo que Lisboa inició en 1668 un llamativo distanciamiento de las grandes cuestiones que condicionaban las relaciones de las potencias mayores que, sin embargo, estuvo lejos de ser un síntoma de desinterés ${ }^{10}$. Muy al contrario, el movimiento respondía a una estrategia protectora, que preveía problemas para el reino en caso de un ataque de la monarquía vecina o una preocupante indefensión si mediante pactos o matrimonios, desmontados sus meditados cálculos, Francia llegaba a respaldar a Madrid, y que en ocasiones acababa incomodando a algunos de los suyos. "Porque no se puede llamar con razón experimentado al piloto que libra la nao después de dar en los escollos, sino a aquel que los antevé para librarse de ellos", diría João da Silva, marqués de Gouveia y embajador de D. Pedro ante Carlos II, entrada la década de $1670^{11}$.

Tanto era así que da Silva, el segundo de los representantes portugueses que pisaba la corte de Madrid tras el reconocimiento de la independencia, entendía que si, como parecía, ningún acuerdo podría evitar un nuevo conflicto entre España y Francia, más valía tomar partido en él directamente ${ }^{12}$. Aunque en verdad ni sus palabras ni las presiones externas que se cernieron sobre la corte lisboeta lograron que el regente abandonase su refugio. Por un lado, para la mayoría su postura no resultaba desconcertante $y$, por otro, los problemas internos que atravesaba Portugal tampoco invitaban a grandes aventuras más allá de sus fronteras.

D. Pedro había alcanzado el poder mediante un golpe palaciego con el que había apartado de los ámbitos de decisión a su hermano, el rey Alfonso $\mathrm{VI}$ —otrora conocido como el Victorioso por sus triunfos frente a España-, si bien sus vacilaciones habían permitido la aparición de una fuerte oposición en el país. Formada por un heterogéneo e invertebrado grupo en el que tenían cabida tanto los partidarios del antiguo régimen como los nuevos descontentos con la política económica del regente así como otros muchos desafectos sin relación evidente con el depuesto, la masa contraria, agrupada genéricamente bajo la etiqueta del alfonsismo (del portugués afonsismo), era tan peligrosa —entendían algunos en Portugal- como los Habsburgo. El príncipe D. Pedro, aseguraba el juez de inconfidencia, Roque Monteiro Paim, se enfrentaba a «dos reyes enemigos, uno dentro

10 MACEDO, s. d., 214/220.

11 Carta del marqués de Gouveia al regente D. Pedro. Madrid, 10 de julio de 1671. Biblioteca da Ajuda (BDA), 49-X-6, ff. 39r-41v.

12 Carta del marqués de Gouveia al regente D. Pedro. Madrid, 18 de julio de 1671. BDA, 49-X-6, ff $78 \mathrm{r}-83 \mathrm{r}$ 
del reino y otro confinante» ${ }^{13}$, y así más valía primero empezar por controlar a los disidentes internos.

La tarea, precisamente por la negativa del regente a recibir la corona en vida de Alfonso VI, resultó, sin embargo, ardua y tuvo que hacer frente incluso a una trama que, aunque atajada a tiempo, puso de manifiesto la inestabilidad del Portugal post-restaurado. Tanto que, conocida como «Conjura de Humanes» por la supuesta participación del conde castellano Baltasar de Eraso y Toledo - titular de la embajada española en Lisboa coincidiendo con la sedición-, si algo demostró la conspiración de 1673, al margen de que el pretendido aislamiento de los Braganza sería fuertemente contestado por los poderes extranjeros en el tablero internacional, fue que incluso se vería amenazado por el traslado de las disputas europeas al día a día del reino ${ }^{14}$. Mal calculado y visible en el caso español, pese a su manifiesto y público deseo de respeto al nuevo orden, y no menos evidente en lo que respecta a Francia, por utilizar la tentativa de revuelta y el miedo que ella generó como una forma con la que presionar al gobierno para conducirle a la guerra contra Madrid. Porque en el fondo que un grupo de disidentes tratase de rescatar a Alfonso VI de su cautiverio en las Azores, donde había sido enviado por su hermano, y buscase su aclamación en el territorio continental no dejaba de ser un asunto que ultrapasaba con creces la geografía de Portugal.

Lo hacía porque el país no ocupaba un espacio tan periférico como cabría imaginar. Apéndice imperfecto en la rivalidad hispanofrancesa de la segunda mitad del siglo XVII, el gobierno de Lisboa contrariando su tendencia huidiza era considerado desde el exterior ora un potencial aliado, ora una parte de la Monarquía católica que quizás podría volver a reintegrarse en su cuerpo central. No en vano, era por ello por lo que los afectos a Francia pretendían «empeñar a los portugueses» en guerra con España desde antes de la conjura ${ }^{15}$, y por lo que, aunque con cautela para no cerrar la puerta a los pactos con el príncipe D. Pedro, las voces de los conspirados llegarían en su momento a ser escuchadas con atención en las altas esferas de $\mathrm{Madrid}^{16}$. En una dialéctica en la que, por momentos, el sujeto principal parecía estar desprovisto de cualquier capacidad de acción en un marco que sistemáticamente venía limitado por los otros.

\section{LA GEOPOLIITICA AJENA}

En 1640 París había saludado con optimismo el levantamiento portugués como una iniciativa que venía a perjudicar directamente a la Monarquía católica,

13 XAVIER y CARDIM, 2008, 262.

14 VALLADARES, 198, 274/ss. MARTÍN MARCOS, 61 (Lisboa, 2011), 67/84.

15 Carta del conde de Humanes a la reina regente. Lisboa, 29 de febrero de 1672. Archivo General de Simancas (AGS), Estado (E), leg. 2621, s. f.

16 Parecer del portugués que vino de Lisboa a Pedro Fernández del Campo. 19 de abril de 1673. AGS, E, leg. 4027, s. f. 
el enemigo con que contendía en plena Guerra de los Treinta Años. Había enviado entonces apoyos a los sublevados y dado cabida en su corte a representantes lusos. Pero el abandono que Lisboa habría sentido de los Borbones en el momento de la firma del tratado de los Pirineos con Madrid, en 1659, dejando a los rebeldes a su suerte, por más que Luis XIV hubiese pretendido mantener en secreto esa cláusula, habría provocado que el ascendiente francés hubiese disminuido a orillas del Tajo hasta el punto de no poder no ya convencer a Lisboa para que siguiese la lucha, sino ni siquiera interceder en las negociaciones que pusieron fin a la contienda.

No obstante, incluso así, la débil y menguante llama de las armas en Portugal fue siempre mejor considerada que el periodo de calma que se iniciaría inmediatamente después. Los años de batallas a uno y otro lado de la Raya habían conformado una época que había situado a la Monarquía católica frente a la corte de Lisboa. En la que Francia, pese a sus «traiciones» y golpeada ahora por la mala noticia de la paz hispanolusa de 1668, había estado más próxima a los Braganza de lo que jamás lo habían estado los Habsburgo, y ésa había sido la razón que había conducido a interpretar ese escenario de crispación como el objetivo último que París se fijaba para con Lisboa ya antes de que la contienda concluyese. Exactamente cuando la llegada del regente D. Pedro al poder había rescatado el mantra de un frente compartido contra Madrid que más pronto que tarde, se decía, habría de conducir a una paz «buena y común» para Portugal enmarcada en la que Francia, victoriosa frente a España en la conocida como Guerra de Devolución, habría de firmar ${ }^{17}$. Por eso, aunque es cierto que no fue así y pese a que a la postre el acuerdo hispanoluso fue estrictamente particular, en adelante los pasos de todos los embajadores de Luis XIV en Lisboa fueron encaminados inequívocamente a desestabilizar la relación de los Braganza con la Monarquía católica aprovechando oportunidades como la brindada por el conde de Humanes.

El recurso al pánico ante una invasión española que jamás llegaría a desaparecer en el Portugal post-restaurado fue así el arma más utilizada por Francia en su estrategia. El miedo, como aglutinante de la colectividad frente a un enemigo externo, era en los tiempos modernos un activo fundamental para la cohesión social ${ }^{18}$, y París no dudó en apoderarse de él para predisponer al pueblo contra España. Claro que el recuerdo de la desolación y las armas pesaba casi tanto o más que la auto-afirmación de los propios lusos, y a los intentos de los embajadores del Cristianísimo por alterar la calma del común de los portugueses, siguieron casi siempre trabas y recelos a una contienda que podría provocar grandes dispendios y sufrimientos. Por más que el enviado de Luis XIV, monsieur d'Aubeville, comentase que concedería «todo lo que pareciere es menester para los gastos

17 Pratica entre o secretario de Estado P. Vieyra da Sylva e o abbade s. Rome [Saint-Romain], embaixador ordinario de El Rey Christianissimo na Corte de Lisboa. Lisboa, 14 de enero de 1668. Biblioteca Nacional de Portugal, Lisboa (BNL), Manuscritos Reservados, cod. 11371, ff. 105r-108r.

18 DELUMEAU, 1989 
della sin que se agravien los Pueblos y que su Rey subprenderá Zeuta y la dará a Portugal y en la India ayudará para que cobren de holandes lo que tienen», la opinión generalizada, se había asegurado ya en la primavera de 1672 , era que no convenía la guerra con España ${ }^{19}$.

La de la calma era la opción que enarbolaba la regencia de D. Pedro, y sin el concurso del gobierno luso, tuvo que ser casi siempre entre fidalgos mancillados y militares desatendidos o de segunda fila donde los embajadores de Luis XIV buscasen y recabasen apoyos. Favorecidos con cargos y prebendas durante las décadas de lucha con España, muchos de los hombres que habían guerreado contra la Monarquía, se sentían, en efecto, marginados ante la estrategia pedrista, y no había tardado en extenderse en Lisboa la idea de que, «degradados con la paz de los intereses que tenían con la guerra, la desea[ba]n y procura[ba]n»20. Era un caldo de cultivo aceptable para París, y d'Aubeville, llegado a la ciudad al tiempo que Humanes, pese a considerar que los apoyos no eran del todo suficientes, no dudó en hacer un guiño a esos sectores presentando, al hilo de las inculpaciones al conde por su participación en la conjura, un memorial al regente en que le instaba a unirse a Francia en la guerra que había comenzado contra los holandeses, quienes, se presumía, habrían de contar con el apoyo de España. Se trataba, decía, de romper «cuanto antes le fuere posible» con Madrid «para lo qual el Rey mi señor le ayudará como lo ha hecho por lo pasado» ${ }^{21}$.

Sus palabras, sin embargo, estaban lejos de ser bien recibidas. A excepción del poderoso y pro-borbónico duque de Cavadal, que, casado en terceras nupcias con una princesa francesa, defendió la propuesta justificando que la de Luis XIV era «la única monarquía que hoy florecía en Europa», en la reunión del Conselho de Estado que examinó la petición, todos los participantes rechazaron con vehemencia la alianza. No solamente era «muy nociva al estado en que se halla Portugal, de poderse empeñar en conveniencias ajenas», según comentó el consejero Rui de Moura Teles, sino que podía ofender al gobierno de Londres, «que era fiador de las Pazes entre Portugal y Castilla», recordó el conde de Valdorreis. Por lo que ante lo expuesto, concluiría el anciano marqués de Marialva, si algo importaba era cuidarse de la perniciosa correspondencia de Francia, que una y otra vez «no trataba más que de introducirse en todas las cortes perturbando toda Europa»22.

Con esa fama no es de extrañar que D. Pedro se resguardase tras su habitual mutismo y que d’Aubeville, que antes de hacer pública la propuesta ya había la-

19 Carta del conde de Humanes a la Reina Regente. Lisboa, 18 de abril de 1672. AGS, E, leg. 2621, s. f.

20 Carta del conde de Humanes a la Reina Regente. Sacavem, 15 de febrero de 1672. AGS, E, leg. 2621, s. f.

21 Copia del memorial que monsieur de Obbebile presentó a este Prínzipe en 6 de marzo de 1675. AGS, E. leg. 2629, s. f.

22 Copia del Asiento del Consejo de Estado que se tubo en primero de Abril de 75 en que se vio el memorial que el embiado de Francia dio a este Príncipe en 6 de marzo del mismo año. Lisboa, 2 de abril de 1675. AGS, E, leg. 2629, s. f. 
mentado no ver «alguna apariencia de disposición de esta corona contra España», diese por concluida su misión sin garantizar avances entrado 1675. En el fondo no solamente no se había presentado ante él ocasiones nuevas a la altura de la crisis abierta por Humanes, como había esperado que sucediese «por milagro» ${ }^{23}$, sino que el talante conciliador que el abate Masserati, el sustituto del conde, había impuesto a las relaciones hispanolusas a su llegada a Lisboa, había acabado con cualquier esperanza. Tras asistir años atrás un tanto sorprendido a una conspiración que le habría costado imaginar a su llegada a Portugal, d’Aubeville no había sabido exprimir todo lo que el miedo podía dar de sí, y con el progresivo enfriamiento del alfonsismo y sin nuevas oportunidades de agitar a la opinión pública con la amenaza española, el camino que Francia suponía haber reservado para los Braganza, parecía comenzar a anegarse precisamente en el momento en que la Monarquía católica empezaba también a moderar su imagen ante los lusos.

Cierto es que el hecho de que Madrid pretendiese ofrecer un discurso amable dejando atrás el empleo de símbolos propios de sus antiguos vasallos o alusiones al pasado católico de Portugal ${ }^{24}$, no equivalía a renunciar en su foro interno a pretensiones sobre la corona que ahora se posaba en las sienes de un Braganza a quien su hermano había apartado del poder. Los anhelos por restituir Portugal en la Monarquía no habían desaparecido en la corte, esperanzada aún, como tras la paz de 1668 en que la providencia fuese capaz de «algún lanze tal, que assí como aquel Reyno se perdió en un día, vuelba a reintegrarse en otro» ${ }^{25}$. Aunque el panorama internacional invitaba más que nunca a la discreción. En una Europa en guerra en la que la Monarquía, aliada ahora de las Provincias Unidas, se enfrentaba a Francia y a Inglaterra -interesada en ahogar a su tradicional competidora en el comercio marítimo hasta el punto de abandonar la coyuntural coalición que le había unido a La Haya-, los intentos por ganarse aliados resultaban fundamentales para las aspiraciones hegemónicas a que aspiraba Luis XIV ${ }^{26}$. Y en ese marco, Portugal se presentaba a los ojos de Madrid como una piedra más con la que erigir una muralla frente a Francia.

Era ahí donde se asentaban las prácticas a favor del buen entendimiento promovidas por Masserati, y, por eso, el enviado pronto centró su misión en la promoción de una alianza con los Braganza. Verdad es que no lo consiguió pero el mero hecho de evitar que Lisboa se decantase por los enemigos de la Monarquía acabó siendo considerado un éxito en la gestión del abate, que irritó particularmente a los franceses. Claude de Guénégaud, el embajador elegido para representar los intereses borbónicos en Lisboa a mediados de 1670, debería empeñarse, dictaría

23 Carta de Monsieur d'Aubeville. Lisboa, 9 de febrero de 1675. Archives des Affaires Etrangères (AAEP), Correspondance Politique (CP), Portugal, vol. 13, ff. 191-193.

24 Por ejemplo, siguiendo las indicaciones de Maserati, que pidió retirar las quinas de entre las armas de la Monarquía para evitar embarazos. Consulta del Consejo de Estado. Madrid, 16 de julio de 1677. AGS, E, leg. 2631, n. 30.

25 Consulta del Consejo de Estado. Madrid, 21 de julio de 1668. AGS, E, leg. 2614, s. f.

26 SÁNCHEZ BELÉN, 20 (Salamanca, 1999): 162. 
a propósito Luis XIV, en hacer ver a los portugueses «el grande perjuicio que les resulta de la Paz con España y que por lo menos deben acordarse de la conjuración que se hizo contra el Prínzipe». Una tarea que, en caso de que algún ministro le hiciese ver que Portugal no estaba en condiciones de hacer la guerra, debería ser completada asegurándole que Francia apoyaría a Lisboa con "el mismo celo» que en el pasado ${ }^{27}$. A pesar de que Guénégaud no tardase en informar de que las presiones de la corte de Madrid impedían cualquier logro.

No era para tanto: la acumulación de tropas españolas en la frontera que denunciaría el francés ${ }^{28}$, no tendría en esta ocasión gran eco en Lisboa. Aunque si algo demostraba el tono de preocupación del embajador, era que mientras que París iba experimentando una especie de recelo hacia lo portugués, España parecía irradiar una suerte de tranquilidad en la ciudad del Tajo conforme pasaban los años. En apariencia atrás iban quedando las desconfianzas mutuas y quizás por ello D. Pedro tuvo entonces el descaro de presentar una propuesta de mediación en el conflicto que enfrentaba, entre otros, a Luis XIV y Carlos II, abandonando su pragmático distanciamiento de la política internacional ${ }^{29}$. Se trataba de ejercer de árbitro desde la estricta neutralidad que el regente se había ido forjando desde hacía más de un lustro, y aunque su planteamiento no prosperó, puso de relieve que en el horizonte conciliador de los últimos años de la década de 1670, con los acuerdos de Nimega ya próximos, Portugal se hallaba mucho más cómodo.

Influía probablemente la indiferencia inglesa ante los planteamientos de los Braganza, porque aunque aliada de París en la guerra franco-holandesa, Londres había concedido un trato a Lisboa mucho más discreto y leve que el que le habían dispensado habsbúrguicos y borbónicos en medio de sus enfrentamientos. Los Estuardo, grandes beneficiarios de las alianzas que Portugal había firmado durante la guerra que había seguido al levantamiento contra la Monarquía católica, no solo podían permitirse mantenerse alejados de polémicas sino que de algún modo eran partidarios de no forzar una relación que hasta la fecha se había mostrado sumamente beneficiosa para sus planes. Como resultado del matrimonio entre Carlos II de Inglaterra y Catalina de Braganza en 1661, habían recibido los enclaves de Tánger y Bombay, y, sobre todo, sustentada en previos acuerdos suscritos tanto antes del estallido de la Guerra Civil Inglesa como en época del Protectorado de Oliver Cromwell, libertad de comercio para que sus mercaderes operasen en todas las plazas lusas de ultramar ${ }^{30} ; \mathrm{y}$, por eso, la de Francis Parry (1671-1680) surgía necesariamente como una embajada al margen de las tensiones.

27 Instrucción de que debe usar el señor Guenegaud, mi embiado extraordinario al Príncipe Regente de Portugal. Copia interceptada y traducida por Masserati. Saint Germain, 8 de julio de 1675. AGS, E, leg. 2630, s. f. La instrucción completa en CAIX DE SAINT-AYMOUR, 1886, 128/134.

28 Carta de Claude de Guénégaud a Luis XIV. Lisboa, 28 de abril de 1676. AAEP, CP, Portugal, 15, ff. 85-86. Véase en este monográfico el artículo de Antonio José Rodríguez Hernández.

29 Carta del regente D. Pedro a Luis XIV (ofreciendo la mediación). Lisboa, 3 de agosto de 1676. AAEP, CP, Portugal, 14, f. 21.

30 BORGES DE CASTRO, 1856, 234/258. PRESTAGE, 1935, 130/151. 
Por más que Humanes hubiese asegurado durante su misión que también los ingleses presionaban al regente D. Pedro para que declarase la guerra a las Provincias Unidas, en ningún momento Londres superaría el tesón intimidatorio de los franceses ${ }^{31}$. Pues en el fondo si hacia alguna dirección iban encaminados los pasos de Parry, era hacia una renovación de los acuerdos comerciales con Lisboa ${ }^{32}$. Era ésa la finalidad de su estancia en Portugal, mantener y velar por los intereses que su gobierno se había granjeado en las posesiones de los Braganza, y sin grandes contratiempos en el trato con el regente, el inglés pudo incluso dedicarse, cual diarista despreocupado, a relatar los movimientos de sus homólogos a orillas del Tajo. Desde el descubrimiento de la trama alfonsista a la oposición del pueblo a una guerra con España, pasando por la noticia, ya al final de su época lisboeta, del establecimiento en La Plata de la Nueva Colonia del Sacramento. Un acontecimiento que provocaría gran regocijo en la ciudad pero ante el que él esperaría represalias de Madrid. "Siendo sus primeros descubridores [...] y pese a que los portugueses supongan este río frontera de Brasil, los españoles jamás lo reconocerán", sentenciaría el embajador ${ }^{33}$.

No erraba en su pronóstico pues a la noticia de la fundación le siguió la de su destrucción a manos de las autoridades de Buenos Aires sin siquiera tener que mediar orden metropolitana desde el otro lado del Atlántico. Aunque más que la crisis y el debate que se abrió entonces entre Portugal y España en torno a la legitimidad o no del enclave, interesa, en estas páginas sobre el encaje de Lisboa en la geopolítica europea, el uso que Francia hizo del episodio en su estrategia continental y, por el contrario, la defensa que planteó la Monarquía católica a la ofensiva borbónica. Cómo, en palabras del Consejo de Estado, valiéndose de «la fundación cerca de Buenos Ayres», Guénégaud presionaba para que D. Pedro se alíase con Francia ponderando las fuerzas que «hemos embiado para desaloxarlos» ${ }^{34}$ y cómo para apartar el ascendiente borbónico convenía, se decidiría tras una negociación de urgencia dirigida por el duque de Jovenazo y malquistada por aquél, trasladar las discusiones desde Lisboa a la frontera hispanoportuguesa ${ }^{35}$. Demostrando cómo también en un periodo de paz entre Luis XIV y Carlos II, Portugal podía siempre surgir en un flanco de la Monarquía católica como un casus belli si los representantes del Cristianísimo eran capaces de atraerse al Braganza. A fin de cuentas, era esa una posibilidad más a pesar de que los beneficios que se presumían ante tal movimiento fuesen tan notorios como célebre era la equidistancia que imponía D. Pedro a sus relaciones con los grandes poderes.

31 Carta del conde de Humanes a la Reina Regente. Lisboa, 22 de julio de 1672. AGS, E, leg. 2622, s. f.

32 Memorial of Francis Parry to Dom Pedro. Lisboa, 14 de enero de 1678. British Library (BL), Additional (Add), 34333, f. 1.

33 Carta de Francis Parry a Robert Spencer. Lisboa, 20 de agosto de 1680. The National Archives (TNA), Public Record Office (PRO), State Papers (SP), 89/14, ff. 82-83.

34 Consulta del Consejo de Estado. Madrid, 6 de noviembre de 1680. AGS, E, leg. 4029, s. f.

35 Despacho de Carlos II al duque de Jovenazo. Madrid, 14 de octubre de 1681. AGS, E, leg. 4030, s. f. 


\section{Estrategia vs apariencia}

Existe una profusa literatura acerca de la constante actitud neutral del príncipe D. Pedro que enraíza con los juicios negativos sobre su propia personalidad. Ciertamente la usurpación de esposa y cetro habría provocado en él remordimientos tan fuertes que le habrían impedido, cuando todo estaba a su favor, proclamarse rey de Portugal y desposeer del título a su hermano. Una decisión, la de rechazar la aclamación, que habría dado origen a críticas sobre su supuesta inestabilidad, y que a la postre habría servido para desacreditar, casi siempre desde el exterior, sus continuos rechazos a un posicionamiento franco y abierto en el continente. Ya entonces, al tiempo que en Madrid se había observado con preocupación que el príncipe desposase a su cuñada, pues se esperaba que escogiese una princesa austriaca facilitando así «la reunión de Portugal» ${ }^{36}$, y pese a que en París se había saludado el matrimonio, no se había podido sino lamentar que D. Pedro no hubiese sido capaz de hacerse con todos los atributos del poder y hubiese dejado las puertas abiertas a los descontentos con que más adelante habría de coquetear el conde de Humanes. Según había considerado el abate Saint-Romain, a la sazón embajador de Luis XIV en Lisboa, solo el consejo del papa, ensimismado como estaba el regente, podría hacerle mudar de opinión ${ }^{37}$.

No lo hizo en parte porque los movimientos al respecto no fueron tan decisivos como el francés hubiese deseado. Si bien, el episodio, apelando al poder sancionador de la religión como mejor recurso frente a la vacilación que se achacaba a Pedro de Braganza, acabó por marcar para siempre la imagen del regente. Configuró en él una suerte de perfil bajo, propio de un individuo huidizo y tímido («El Príncipe es particular y se comunica con pocas personas, huye de los asuntos [de gobierno] y tiene poca aplicación» ${ }^{38}$ ), y dio cabida a un lugar común en los testimonios extranjeros. Francis Parry le describió no solamente como un hombre marcado por sorprendentes fluctuaciones en decisiones e inclinaciones y poco capaz para el gobierno, sino demasiado propenso a la aprehensión ${ }^{39}$. Mientras que el conde Ottavio Francesco Solaro, que visitó Lisboa en nombre del duque Carlos Manuel II de Saboya en 1670 para felicitar a la reina María Francisca por su recuperación tras una complicada enfermedad, consideró que aunque «el talento del príncipe no sería malo si hubiese estado cultivado con una buena educación", su gobierno era poco firme y estaba lejos de imponerse a los desafectos ${ }^{40}$.

36 Nouvelles de Madrid. Madrid, 12 de abril de 1668. AAEP, CP, Portugal, 7, ff. 130-133.

37 Memoire de St. Romain au ministre du Roy à Rome. Lisboa, 26 de enero de 1670. AAEP, CP Portugal, 10, ff. 36-39.

38 El testimonio es nuevamente de Saint-Romain, cit. en DORIA, 1944, 282.

39 Carta de Francis Parry a Joseph Williamson. Lisboa, 20 de noviembre de 1669. TNA, PRO, SP, 89/10, ff. 135-136.

40 Rilatione del viaggio fatto in Portugallo. Madrid, 4 de mayo de 1672. Archivio di Stato di Torino (ASTo), Corte, Materie politiche per rapporto all'Estero (MPRE), Lettere Ministri, Spagna, 30, núm. 2, 71/6. 
Se le achacaba en esa época una sumisión a las grandes familias, paralela a una supuesta supremacía del Conselho de Estado en la toma de decisiones de gobierno, en realidad contrarrestado mediante la convocatoria de pequeñas juntas de gobierno que daban voz a la reina y a otros miembros de la nobleza ${ }^{41}$. E incluso tras su aclamación regia después de que en 1683 falleciese su hermano, un jovencísimo marqués de Torcy, enviado extraordinario de Luis XIV para cumplimentar al nuevo monarca, diría a su regreso a París que la misma nobleza que le había encumbrado, le hacía sentir inseguro y atado a sus designios ${ }^{42}$. Una circunstancia que en una fecha tan tardía como 1698, empujaría al futuro estadista Michel de Amelot a considerar que, pese a no faltarle al Braganza «ni espíritu ni argucia», en el fondo todo lo echaba a perder por su lentitud e irresolución ${ }^{43}$. Como sentenciaría el capellán de la factoría británica de Lisboa, John Colbatch, en una densa relación que haría publicar en Londres poco después y que, sin embargo, se dispensaría de firmar, si algo caracterizaba a D. Pedro era ser de «rápida aprehensión y juicio penetrante, prudente, educado, e inclinado a una melancolía» creciente en los últimos años ${ }^{44}$.

Nada que ver con las alabanzas que merecía el príncipe entre los suyos, para quienes D. Pedro encarnaba las mayores esperanzas para que «el Imperio en su esplendor quedase", según un panegírico escrito por el marqués de Arronches con el Braganza ya rey de Portugal ${ }^{45}$. En efecto, desde el golpe con que había apartado a su hermano del gobierno, se había erigido como la gran esperanza para dar continuidad a la monarquía portuguesa, y la idea de fuerza y grandeza de su persona había sido difundida abundantemente por la publicística.

«Muy alto rey, monarca soberano todavía mayor que vuestro mismo Imperio, que en el mar se ciñe, el sol mide y el cielo termina", se había dicho de él coincidiendo con el nacimiento de su hijo, el futuro Juan V, en $1689^{46}$. Aunque no es demasiado atrevido considerar que, frente a la magnanimidad y fuerza de $\mathrm{D}$. Pedro enarbolada por los propagandistas del régimen, los informes de los extranjeros citados anteriormente resultan más fiables. Los testimonios de aquellos no solo no perseguían la exaltación de un sujeto sino que estaban condicionados por la aparente objetividad que les imponía tener que referir a sus gobiernos noticias fieles a la realidad portuguesa. Tenían que ser considerados como punto de partida sobre el que desarrollar estrategias políticas. Una pieza básica a partir de la cual cursar instrucciones, definir nuevas líneas de actuación o abortar planteamientos errados, y, por ende, entraban en directa colisión con los opuestos estereotipos que Portugal reservaba para su señor. Si bien, como informaciones di-

41 GAMA, 2012, 146/147.

42 SERRÃO, 1960.

43 LEAL DE FARIA, 2009, 9/10.

44 [COLBATCH], An account, 4.

45 [TAVARES], Panegyrico, 68.

46 LOURENÇO, 2007, 131. 
rectas sobre el Braganza a menudo debieron de ser sobrevalorados por sus propios contemporáneos a la hora de comprender los en teoría dubitativos pasos de la corte de Lisboa.

En un debate en el que el desconcierto de los portugueses frente a las intenciones de Austrias y Borbones parecía haber adquirido rango de verdad inalienable, es muy probable que de fronteras para fuera el gobierno tratase de sacar partido a su teórica indefinición. Parapetado tras sus supuestas dudas, Portugal no hacía sino reforzar durante la regencia su postura de máxima neutralidad - concepto tradicionalmente demonizado por el maquiavelismo-, y nada hizo para combatir una imagen que en Europa podía no dejar en muy buen lugar al príncipe D. Pedro. Pese a algunas divergencias, era opinión generalizada en el país la apuesta por la paz y no solamente para evitar ataques que pudiesen poner en jaque la integridad territorial de las posesiones lusas. Para el embajador portugués en París, Duarte Ribeiro de Macedo, el asunto iba mucho más allá. En tiempos de Francisco I y Carlos $V$, según había recordado en un oficio enviado a la corte de Lisboa en 1672, también se había solicitado a los Avis, a la altura la dinastía reinante en Portugal, una alianza, y únicamente su firme negativa había valido para que el reino, al margen de polémicas y guerras que se extendían por Europa, se hubiese enriquecido «con comercios y conquistas», que «de estas y de aquellos debemos tratar mucho», había sentenciado el embajador ${ }^{47}$.

La referencia a las empresas militares hacía volver la vista hacia ultramar casi inevitablemente. Con un imperio en recesión en oriente, la expansión hallaba una base sólida sobre la que seguir avanzando en el vértice americano de un triángulo compuesto por Portugal, África y Brasil ${ }^{48}$. Era ahí donde, pese al freno que había supuesto el fin de la Unión Ibérica para algunas de sus poblaciones, que habían visto interrumpido drásticamente el flujo de la plata peruana, la corte lisboeta había fijado sus objetivos. Consolidando sus posesiones y avanzando tanto al sur de Rio de Janeiro como al norte de Salvador de Bahía, estaba llamada no solo a proteger un área económica de excepción, que no mucho después sustituiría el ciclo del azúcar por el más ambicioso y pujante del oro, sino a restaurar ya fuera mediante el contrabando o vínculos legales su acceso a las riquezas que los españoles se reservaban en América. Cuán conveniente sería para las dos monarquías ibéricas «el ensanche del comerzio de las Indias», habían defendido los lusos ante Madrid ya a comienzos de la década de $1670^{49}$. O, por qué no, una alianza hispanoportuguesa que prohibiese el comercio con los franceses ${ }^{50}$. Desde esa perspectiva, al margen de las lecturas que habían querido hacer los extranjeros, Sacramento constituía un afianzamiento en la estrategia brasileña de D. Pedro

47 Oficio de Duarte Ribeiro de Macedo a Francisco Correia de Lacerda. París, 28 de febrero de 1672, cit. en LEAL DE FARIA, 2007, 343/345.

48 BOXER, 1969, 128/176. MAURO, 1983.

49 Consulta del Consejo de Estado. Madrid, 22 de enero de 1671. AGS, E, leg. 2619, s. f.

50 Minuta de despacho de Carlos II a Francisco Enríquez Dávalos [en respuesta a carta del embajador fechada el 24 de agosto de 1683]. Madrid, 16 de septiembre de 1683. AGS, E, leg. 4053, s. f. 
como a la postre lo sería las negociaciones con Francia para hacerse con la exclusiva de la navegación en el Amazonas a cambio de apoyar a los Borbones en la crisis sucesoria de la Monarquía de España ${ }^{51}$. Y fue así como lo entendieron los propios portugueses en su defensa de Brasil.

En Europa, el comercio era, en cambio, un factor algo más complejo. En apariencia en un contexto bélico Portugal podría sacar partido a su neutralidad mediante incentivos a la actividad mercantil, como entendía Ribeiro de Macedo. Aunque lo cierto es que no habría en adelante grandes cambios en una balanza que, demasiado condicionada por los acuerdos que los Braganza habían suscrito durante la Guerra de Restauración con Londres o La Haya, se antojaba poco favorable para sus intereses. Tras años de paz mientras el resto de países se había visto envuelto en luchas y batallas, «sería de esperar [que] las cosas tuviesen buen aspecto como si hubiese muchas riquezas entre ellos, así como una buena circulación de comercio enérgico, pero, en vez de eso, apenas veo lo contrario», referiría sorprendida una fuente inglesa ya a comienzos del XVIII ${ }^{52}$. En el fondo, que en el continente, a diferencia de lo que sucedería en la expansión ultramarina, Portugal no consiguiese grandes avances en el terreno económico no era sino el resultado del precio que había tenido que pagar por su independencia en los años de la contienda con España. Por lo que únicamente la apuesta por la paz, sin apenas contrariar con otras iniciativas novedosas a los grandes poderes, se mantuvo como prioridad destacada en el Viejo Mundo. «No cambiar nada en su conducta» es la «resolución de esta corte», observaría el embajador John Methuen cercano el cambio de siglo ${ }^{53}$.

A partir de la neutralidad se podían preservar las posesiones americanas y consolidar el reconocimiento, y esos fueron los ejes sobre los que osciló la política exterior de D. Pedro y también el motivo por el que la elección del pretendiente ideal para su hija Isabel Luisa Josefa habría de convertirse, como el posicionamiento de Portugal en el continente, en un asunto de perenne irresolución. Heredera presunta al trono tras ser jurada por las cortes como princesa de Beira en enero de $1674^{54}$, la entonces hija única del regente era con poco más de cinco años una codiciada dama. Sin hermanos, algún día la corona que tantos recelos despertaba en el regente podría llegar a posarse sobre sus sienes. La posibilidad despertaba gran interés en Europa. Era el medio más eficaz para estrechar lazos con los Braganza, conducirlos incluso a empresas que de otra manera rechazarían constantemente, y tan solo dos años después ya se rumoreó en Lisboa que París había emprendido diligencias para que fuese el Delfín quien desposase a la

51 SZARKA, 1976, 237/244

52 COX y MACRO, Relação do Reino, 262.

53 Carta de John Methuen al duque de Shrewsbury. Lisboa, 31 de marzo de 1696. TNA, PRO, SP, 89/17, ff. 218-219.

54 Relation Du Jurement d'Isabelle Marie Infante de Portugal fait à Lisbone le 20 Janvier 1674 en l'assemblée generale des Cours du dit Royaume tratuite de portugais en françois. AAEP, CP, Portugal, vol. 13, ff. 35-37. 
princesa. Alarmado, el abad Maserati refirió entonces haberse reunido con altas personalidades del régimen, «interiormente poco afectos a la Francia», para significarles los peligros que el enlace escondía ${ }^{55}$. El gobierno, supo de inmediato, barajaba también como pretendientes algunos sujetos de los ducados de Toscana y Baviera por ser menos comprometedores ${ }^{56}$.

Con el paso del tiempo ninguna de esas tres opciones fructificó. La solución pasaba por una especie de vuelta a los orígenes, y la corte de Lisboa terminó fijándose en la corte de Turín. Tras los matrimonios de María Francisca de SaboyaNemours con Alfonso VI y, después, con el regente D. Pedro, en un ejercicio de ambición de la soberana no solo por reinar sino también por gobernar ${ }^{57}$, ambos gobiernos habían estrechado lazos y que la apuesta piamontesa fructificase no dejaba de ser una salida tranquilizadora frente a los debates que el matrimonio de Isabel Luisa podía deparar. Aunque el asunto se trató con el máximo secreto, por un lado, suponía un guiño hacia Luis XIV que la veterana reina fuese capaz de desplegar su ascendiente en Lisboa y, por otro, se enmarcaba dentro de una tendencia cuasi natural frente a la que poco podía protestar la Monarquía católica por más que desease otras salidas. Por lo que Maserati apenas sí pudo optar por guardar silencio cuando a partir de 1678 se iniciaron las negociaciones para unir en matrimonio a la infanta portuguesa y el duque Víctor Amadeo II de Saboya.

Solo entrados los años ochenta, cuando inesperadamente el acuerdo se rompió, quizás por entender el príncipe piamontés que los negociados respondían a la voluntad de su madre de apartarlo de la corte turinesa ${ }^{58}$ o quizás por una serie de malentendidos y desacatos promovidos por algunos sectores de la nobleza lusa ${ }^{59}$, las presiones extranjeras regresaron a Lisboa. En la elección de un marido para la princesa, molesta la alta nobleza por la humillación italiana y los altos gastos de la empresa frustrada, Saboya ya no era un lugar donde refugiarse, como tampoco lo sería en 1683 cuando falleciese la reina María Francisca tan solo unos meses después de que lo hiciese Alfonso $\mathrm{VI}$, su primer marido. En ese momento, coronado por fin el otro Braganza como Pedro II y finiquitada la tumultuosa época de la regencia, la voluntad del nuevo monarca de mantenerse alejado de los grandes poderes - cierto es que golpeado por el deceso de su esposaharía que la elección de su segunda mujer, esta vez una joven princesa del Imperio lo suficientemente distante de los Austrias españoles, todavía hubiese de prolongarse durante años ${ }^{60}$. Además, que su hija, conocida ya entonces como la

55 Carta del abad Maserati a la Reina Regente. Lisboa, 23 de julio de 1676. AGS, E, leg. 2630, exp. 108.

56 Carta del abad Maserati a la Reina Regente [otra]. Lisboa, 23 de julio de 1676. AGS, E, leg. 2630, exp. 113.

57 GODINHO, 2009, 465.

58 CONTESSA, 1936, 80/142.

59 Carta del conde Marcello de Gubernatis a la Madama Reale. Lisboa, 1 de diciembre de 1682. ASTo, Corte, MPRE, Lettere ministri, Portogallo, 2, s. f. No obstante, sobre los particulares de este asunto, véase OSBORNE, 2012, 211/238.

60 BRAZÃO, 1936. 
Sempre Noiva, falleciese soltera en 1690, superada en la línea de sucesión al trono tras el nacimiento del futuro Juan $\mathrm{V}$, no haría sino clarificar hasta qué punto el deseo de mantenerse neutrales e independientes había condicionado a los miembros de la dinastía de Braganza.

\section{UNA REGENCIA SINGULAR}

"Con que será este Príncipe (ya Rey) más absoluto de lo que permitían las contemplaciones que tenía a los parciales de su hermano", escribió Tomás Enríquez Dávalos el 13 de septiembre de 1683 dando cuenta de la muerte de Alfonso VI la tarde anterior ${ }^{61}$. Informando del deceso desde Lisboa, el enviado de la Monarquía dejaba entrever que atrás quedaban los miedos y los recelos a la oposición, y lo hacía como si la muerte del monarca supusiese un triunfo para D. Pedro. En el fondo no estaba equivocado. Sin él el alfonsismo perdía su referente y su justificación última ante la opinión pública, y aunque los heterogéneos descontentos siguieron alentados desde Madrid y el deseo de la vuelta a la tutela de los Habsburgo vivo en algunos sectores ${ }^{62}$, conseguir la corona y de paso sobrevivir a tres lustros de tensiones fue visto como un acontecimiento que mereció, emboscados en el luto, discretos elogios de sus contemporáneos.

Las palabras del español descubrían que antes de su aclamación como Pedro II, el Braganza había tenido que hacer frente a no pocos problemas y aunque, como era de esperar, no hablaban del intrusismo del gobierno de Madrid o del de Francia en la política interna de Lisboa, resulta difícil no rescatar esa idea. Las intervenciones de los grandes poderes habían supuesto un escollo de primer orden para el regente, y haber evitado que Portugal participase de sus conflictos constituía todo un logro. Sin celebraciones al respecto en los quince años que habían seguido a la deposición de Alfonso VI, la calma había sido sinónimo de acierto, y sería ese el estadio sobre el que el nuevo monarca sería capaz de construir una nueva época en la que progresivamente el reino iría dejando atrás un aislamiento a medio camino entre el voluntarismo y la obligación. Por lo que entender el tiempo de la regencia como una época de difícil pero feliz consolidación se exige casi como un paso indispensable para comprender las ulteriores pretensiones portuguesas ante la sucesión española y el propio afianzamiento de la dinastía en Europa.

La llegada de D. Pedro al poder en detrimento de su hermano había sido publicitada por sus partidarios como la única forma con que garantizar la independencia conquistada a los españoles tras años de guerra y el futuro de la monar-

61 Carta de Francisco Enríquez Dávalos a Carlos II. Lisboa, 13 de septiembre de 1683. AGS, E, leg. 7060, s. f.

62 SERRÃO, 1960, 19. 
quía. Así se defendía en Catastrophe de Portugal ${ }^{63}$, una obra de carácter propagandístico atribuida a Francisco Correia de Lacerda, y ese era también uno de los logros que, quince años más tarde, cabía reconocer. Si, como se decía en sus páginas, el maleable Alfonso VI había supuesto una amenaza para los avances conquistados durante la Restauração portuguesa, la simple conservación de la monarquía llevada a cabo por D. Pedro era el mayor de sus logros. Bien mirado, poco importaba contar o no con grandes victorias cuando los suyos casi siempre habían exigido la paz. Las pocas voces que habían reclamado la entrada de Portugal en guerra, es verdad que altisonantes, habían correspondido por norma general a militares desprovistos de la gloria y el estatus que les había otorgado la guerra con España, y en ningún momento habían conseguido imponerse a quienes demandaban calma. Es más, desvanecidas en el ocaso del alfonsismo, ya apenas volverían a resurgir, como si sucumbiesen ante la propia mutación de D. Pedro.

De recatado y tímido en sus orígenes políticos a pretencioso y altivo en sus últimos años, el cambio hoy parece demostrar la existencia de varios D. Pedro a lo largo del tiempo. Segundo en la línea de sucesión al trono de Portugal durante su infancia y juventud y encumbrado por un grupo de la nobleza al poder tras apartar al valido de su hermano, el conde de Castelo Melhor y, de inmediato, al propio Alfonso VI, el Braganza que asume la regencia da la sensación de no tener nada que ver con el que se corona rey. Cada vez más desacomplejado a partir de 1683 y en cierto modo demasiado ambicioso en sus planteamientos ya a finales del Seiscientos, que ante la crisis dinástica de la Monarquía de España reclamase un sitio para Portugal en los tratados de partición ${ }^{64}$, descubre hasta qué punto había servido la estrategia taciturna que había seguido a la Guerra de Restauración. Poco importa en este discurso que finalmente Lisboa quedase fuera de los repartos o que el reconocimiento de un Borbón en el trono de Madrid le brindase una nueva oportunidad de obtener beneficios territoriales aprovechando la crisis sucesoria española; que luego abandonase su alianza con Luis XIV y se desdijese de sus afirmaciones o que se decantase, bajo la severa mirada de Inglaterra, por los Habsburgo en la Guerra de Sucesión. Más allá de unos movimientos en parte condicionados por la vorágine del nuevo siglo que golpeaba al país desde el exterior, la mera presencia de Portugal en los grandes escenarios del panorama internacional, ya fuera central o secundaria, ratificaba su propia existencia como poder independiente en la Europa del Barroco otorgándole una nueva visibilidad.

Quizás los silencios de la regencia que tanto habían incomodado a algunos solo habían sido un estadio necesario. Una etapa de transición o preparatoria que hoy puede entrar en colisión con el concepto de neutralidad que habitualmente se ha asociado al Portugal posterior a la Restauración. Frente a la idea clásica según la cual el lugar natural para el gobierno de Lisboa habría sido un espacio aparti-

63 [LACERDA], Catastrophe, 167.

64 PERES, 1931, 19/20. 
dista siendo la Guerra de Sucesión española un hiato que en nada favorecería al ultramar portugués —el tesoro a preservar- ${ }^{65}$, los movimientos de Pedro II parecen rebelarse ante una sumisión presupuesta. Como si demostrasen que los quince años en que había detentado el poder en vida de su hermano Alfonso VI habían escondido algo más que la simple conservación que se asocia a las regencias en una decadencia programada que se prolonga lentamente hasta su desaparición.

No en vano, desde el mismo momento en que se había hecho con el poder, el D. Pedro regente había estado llamado a ocupar algún día el trono de su hermano como rey absoluto, y esa característica le dotaba de una peculiaridad única frente al universo de regencias de la Europa del siglo XVII. A diferencia de los más comunes modelos femeninos de este fenómeno, en que las madres-regentes estaban llamadas a ejercer de protectoras de los futuros soberanos, él no había debido proteger a un vástago que en el futuro acabaría con su poder, y, por eso, a medida que su regencia había ido tocando a su fin, se había ido haciendo más poderoso. Frente a la aparición de tensiones y grupos opositores inherentes a una progresiva pérdida de fuerza como había sucedido en los reputados casos de María de Medici y su contemporánea Mariana de Austria ${ }^{66}$, el movimiento de Pedro de Braganza había descrito una órbita opuesta. Pues, aunque muy convulso en sus inicios, si de algo le había servido el paso del tiempo, había sido para afianzar su figura en el poder y la de los que le habían aupado.

No podía ser de otra manera. Su naturaleza, sin el condicionante del género, había respondido a otras variables y como un regente que habría de ser rey, el Braganza había vivido una época de afianzamiento que había desembocado en una gloriosa aclamación. Un paso complicado que hasta a él mismo le había hecho dudar pero que a la postre había acabado dando resultado. A diferencia de lo que sucedía en las regencias ortodoxas, en las que finalidad y duración, por más que el poder en ocasiones sirviese para garantizar una influyente pervivencia de sus titulares, solían ser elementos cuidadosamente definidos ${ }^{67}$, en su caso ninguno de esos condicionantes había encontrado acomodo. Por un lado, su título de regente había sido estrictamente anterior a su proclamación regia y consecuentemente había resultado contraproducente cuando no peligroso limitar sus propios objetivos una vez que estaba llamado a reinar. Por otro, nadie había podido establecer un límite para su gobierno pues no solamente el fallecimiento de su hermano era un hecho impredecible sino que él era su propio sucesor. Solo así se entendía que Dávalos, el embajador español que había dado la noticia de la muerte de Alfonso VI a Madrid, hubiese dicho del gobierno del portugués que a partir de ese momento sería más absoluto de lo que ya lo era. Si la regencia de D. Pedro había sido un estadio transitorio, lo había sido para él propio.

65 BOXER, 1969, 158/159.

66 CRAWFORD, 2004. OLIVÁN, 2006.

67 CAMPBELL ORR, 2004, 8. 


\section{BIBLIOGRAFÍA}

BORGES DE CASTRO, José Ferreira, Collecção dos tratados, convenções, contratos e actos publicos celebrados entre a coroa de Portugal e as mais potencias desde 1640 até ao presente, Lisboa, Imprensa Nacional, 1856, vol. 1.

BOUZA, Fernando, Portugal en la Monarquía hispánica (1580-1640). Felipe II, las cortes de Tomar y la génesis del Portugal Católico, Madrid, tesis doctoral inédita, Universidad Complutense, 1987, vol. I.

- "Lisboa sozinha, quase viuva. A Cidade e a Mudança da Corte no Portugal dos Filipes», Penélope. Fazer e desfazer a História, 13 (Lisboa, 1994): 71/93.

BOXER, Charles R., The portuguese seaborne empire, 1415-1825, Londres, Hutchinson, 1969.

BRAZÃO, Eduardo, O casamento de D. Pedro II com à princesa de Neuburg (documentos diplomáticos), Coimbra, Coimbra Editora, 1936.

CAIX DE SAINT-AYMOUR, Amédée de, Recueil dês instructions aux ambassadeurs et ministres de France depuis les traités de Westphalie jusqu'a la Révolution Française. III. Portugal, París, Félix Alcan Éditeur, 1886.

CAMPBELL ORR, Clarissa (ed.), Queenship in Europe, 1660-1815. The Role of the Consort, Cambridge, University Press, 2004.

CARDIM, Pedro «Os "rebeldes de Portugal" no congresso de Münster (1644-1648)», Penélope. Fazer e desfazer a História, 19-20 (Lisboa, 1998): 101/128.

COLBATCH, John, An account of the Court of Porutgal under the Reign of the present King Dom Pedro II with some discourses on the Interests of Portugal, with regard to other sovereigns; containing a relation of the most considerable transactions that have pass'd of late between that Court, and those of Rome, Spain, France, Vienna, England, \&c., Londres, Thomas Bennet, 1700.

CONTESSA, Carlo, «La congiura del marchese di Parella (1682)», Bolletino storico-bibliografico subalpino, XXXVIII (Turín, 1936): 80/142

COSTA, Leonor Freire, Da Restauração a Methuen: ruptura e continuidade, en José Luis Cardoso et alii, O Tratado de Methuen (1703), Lisboa, Horizonte, 2003: 31/49.

COX, Thomas, y MACRO, Cox, Relação do Reino de Portugal, 1701. Edición y coordinación de Maria Leonor Machado de Sousa. Lisboa, Biblioteca Nacional, 2007.

CRAWFORD, Katherine, Perilous Performances: Gender and Regency in Early Modern France, Cambridge, Harvard University Press, 2004.

DELUMEAU, Jean, El miedo en Occidente (siglos XIV-XVIII): una ciudad sitiada, Madrid, Taurus, (1978) 1989.

DORIA, António Álvaro, A Rainha D. Maria Francisca de Sabóia (1646-1683), Oporto, Livraria Civilização, 1944.

FERNÁNDEZ ALBALADEJO, Pablo, «Imperio y administración bajo Carlos V: una reevaluación», en Hernán Cortés y su tiempo, Mérida, Editora Regional de Extremadura, 1987: 520/527.

GAMA, Maria Luisa Marques da, O Conselho de Estado no Portugal restaurado-teorização, orgânica e exercício do poder político na corte brigantina (1640-1706), tesis de máster inédita, Lisboa, Universidade de Lisboa, 2012.

GODINHO, Vitorino Magalhães, «1580-1640 — Da União Dinástica à Restauração» (1ª ed., 1968), en Vitorino Magalhães Godinho, Ensaios e estudos. I. Uma maneira de pensar, Lisboa, Sá da Costa Editora, 2009: 421/468.

HESPANHA, António Manuel, "O Governo dos Áustria e a 'modernização' da Constituição Política portuguesa», Penélope. Fazer e desfazer a História, 2 (Lisboa, 1989): 49/74.

[LACERDA, Francisco Correia de], FARIA, Leandro Dorea Caceres e Catastrophe de Portugal na deposição del rei Affonso VI e subrogação do príncipe D. Pedro o Unico, justificada nas calamidades publicas escrita para justificação dos portugueses, Lisboa, Miguel Manescal, 1669. 
LEAL DE FARIA, Ana Maria Homem, Duarte Ribeiro de Macedo. Um diplomata moderno, 16181680, Lisboa, Instituto Diplomático, 2005.

- Os Cadernos de Duarte Ribeiro de Macedo. Correspondência Diplomática de Paris, 16681676, Lisboa, Instituto Diplomático, 2007.

- D. Pedro, o Pacífico. Dinastia de Bragança, 1683-1706, Matosinhos, QuidNovi, 2009.

LOURENÇO, Maria Paula Marçal, D. Pedro II, Rio de Mouro, Círculo de Leitores, 2007.

MACEDO, Jorge Borges de, voz «Nobreza (na Época Moderna)», en Joel Serrão (dir.), Dicionário de História de Portugal, Lisboa, Iniciativas Editoriais, 1971, vol. III: 152/158.

- História diplomática portuguesa. Constantes e linhas de Força, Lisboa, Instituto da Defensa Nacional, s. d.: 214/220.

MARQUES, Guida, «O Estado do Brasil na Uniâo Ibérica: dinámicas políticas no Brasil no tempo de Filipe II de Portugal', Pénélope. Revista de Historia e Ciencias Sociais, 27 (Lisboa, 2002): 7/35.

MARTÍN MARCOS, David, «Visiones españolas de algunos anhelos prohibidos en el Portugal de los Braganza: en torno a una nueva Unión Ibérica», Ler História, 61 (Lisboa, 2011): 67-84.

MAURO, Frédéric, Le Portugal, le Bresil et l'Atlantique au XVIle siècle (1570-1670), París, Foundation Calouste Gulbenkian-Centre Culturel Portugais, 1983.

MIRANDA, Tiago C. P. dos Reis, “"Estrangeirados”. A questão do isolacionismo português nos séculos XVII e XVIII», Revista de História, 123-124 (São Paulo, 1990/1991): 35/70.

MONTEIRO, Anabela Nunes, «Repercussions of the Relationship between Portugal and Spain in Macao and the Philippines during the Third Royal Portuguese Dynasty (1580-1640)», en Macao-Philippines Historical Relations, Macao, University of Macao-CEPESA, 2005: 111/124.

OLIVÁN, Laura, Mariana de Austria. Imagen, poder y diplomacia de una reina cortesana, Madrid, Universidad Complutense de Madrid, 2006.

OSBORNE, Toby, «Nôtre Grand Dessein»: O projecto de casamento entre o duque Vítor Amadeu e a infanta Isabel Luísa e a política dinástica dos Sabóias (1675-82), em Maria Antónia Lopes y Blythe Alice Raviola (eds.), Portugal e o Piemonte: a Casa Real Portuguesa e os Sabóias, Coimbra, Imprensa da Universidade de Coimbra, 2012: 211/238.

PERES, Damião, A diplomacia portuguesa e a Sucessão de Espanha, Barcelos, Portucalense, 1931.

PRESTAGE, Edgar, «The Treaties of 1642, 1654 and 1651», en Edgar Prestage, Chapters in Anglo-Portuguese Relations, Watford, Voss and Michael, 1935:130/151.

RUIZ IBÁÑEZ, José Javier y SABATINI, Gaetano, «Monarchy as conquest: violence, social opportunity and political stability in the establishment of the Hispanic Monarchy", The Journal of Modern History, 81 (Chicago, 2009): 501/536.

SÁNCHEZ BELÉN, Juan Antonio, «Las relaciones internacionales de la Monarquía Hispánica durante la regencia de doña Mariana de Austria», Studia Historica. Historia Moderna, 20 (Salamanca, 1999): 137/172.

SERRÃO, Joaquim Veríssimo Uma relação do reino de Portugal em 1684, Coimbra, Universidade, 1960.

SZARKA, Andrew Stephen, Portugal, France, and the coming of the War of the Spanish Succession, 1697-1703, tesis doctoral inédita, Columbus, Ohio State University, 1976.

[TAVARES, Henrique de Sousa], Príncipe Senescal de Ligne, marqués de Arronches, Panegyrico al Rey nuestro señor de Portugal, Lisboa, Miguel Deslandes, 1685.

TORGAL, Luis Reis, Ideologia política e Teoria do Estado na Restauração, Coimbra, Biblioteca Geral da Universidade, 1981: 113/114.

VALLADARES, Rafael, La rebelión de Portugal. 1640-1680. Guerra, conflicto y poderes en la Monarquía hispánica, Valladolid, Junta de Castilla y León, 1988.

- La conquista de Lisboa. Violencia militar y comunidad política en Portugal, 1578-1583, Madrid, Marcial Pons, 2008.

XAVIER, Ângela Barreto y CARDIM, Pedro, D. Afonso VI, Lisboa, Temas e Debates, 2008. 